\title{
Validação de marcadores moleculares associados à resistência à ferrugem marrom em cana-de-açúcar
}

\author{
Fernanda Zatti Barreto ${ }^{1}$, Thiago Willian Almeida Balsalobre ${ }^{1}$, Roberto Giacomini Chapola ${ }^{1}$, \\ Hermann Paulo Hoffmann ${ }^{1}$, Monalisa Sampaio Carneiro ${ }^{1}$.
}

\begin{abstract}
${ }^{1}$ Universidade Federal de São Carlos, Centro de Ciências Agrárias, Araras-SP, Brasil. Autor de correspondência: Monalisa Sampaio Carneiro (monalisa@cca.ufscar.br) Data de chegada: 22/11/2016. Aceito para publicação em: 14/02/2017.
\end{abstract}

$10.1590 / 0100-5405 / 168917$

\section{RESUMO}

Barreto, F.Z.; Balsalobre, T.W.A. Chapola, R.G.; Hoffmann, H.P.; Carneiro, M.S. Validação de marcadores moleculares associados à resistência à ferrugem marrom em cana-de-açúcar. Summa Phytopathologica, v.43, n.1, p.36-40, 2017.

A ferrugem marrom causada pelo fungo Puccinia melanocephala é uma importante doença em cana-de-açúcar (Saccharum spp.) e está presente em praticamente todas as áreas de cultivo. Um gene de efeito maior, Bru1, foi descrito como fonte de resistência durável da cana-de-açúcar contra isolados de P. melanocephala. O objetivo deste estudo foi avaliar a eficiência de dois marcadores moleculares fortemente associados ao gene Bru1, R12H16 e 9O20-F4-RsaI, para predição da resistência genética à ferrugem marrom em variedades de cana-de-açúcar. Para tanto, foram utilizadas neste estudo 14 variedades RB, desenvolvidas pela RIDESA (Rede Interuniversitária para o Desenvolvimento do Setor Sucroenergético), as quais estão entre as 10 mais cultivadas na região Centro-Sul do Brasil no período de 1974 a 2015. Para avaliação da doença a campo foi conduzido um experimento em blocos casualizados com quatro repetições. A severidade da ferrugem marrom foi quantificada de acordo com escala diagramática que varia de 1 (mais resistente) a 9 (mais suscetível) e os dados obtidos foram analisados através de modelo misto linear generalizado (GLMM). Concomitantemente, foi extraído o DNA total das 14 variedades e, em seguida, foi realizada amplificação dos marcadores moleculares, que foram classificados em haplótipos. Do total de variedades, 12 não mostraram sintomas da doença e, através da análise via GLMM, apresentaram probabilidade de 99,35\% de serem resistentes; destas, 91,66\% foram haplótipo 1, ou seja, tiveram a presença de ambos os marcadores associados ao gene Bru1. Portanto, podese concluir que os marcadores moleculares R12H16 e 9O20-F4-RsaI foram altamente eficientes em predizer fenótipos resistentes e que provavelmente $\mathrm{o}$ gene $B r u 1$ seja a principal fonte de resistência de cana-de-açúcar à ferrugem marrom nos campos comerciais do Brasil.

Palavras-chave: Saccharum spp., melhoramento, Puccinia melanocephala, Bru1, resistência à doença.

ABSTRACT

Barreto, F.Z.; Balsalobre, T.W.A. Chapola, R.G.; Hoffmann, H.P.; Carneiro, M.S. Validation of molecular markers associated with brown rust resistance in sugarcane. Summa Phytopathologica, v.43, n.1, p.36-40, 2017.

Brown rust caused by the fungus Puccinia melanocephala is an important disease affecting sugarcane (Saccharum spp.) and is present in almost all growing areas. A major effect gene, Bru1, was described as a durable resistance source in sugarcane against isolates of $P$. melanocephala. The aim of this study was to evaluate the efficiency of two molecular markers strongly associated with Bru1 gene, R12H16 and 9O20-F4-RsaI, for prediction of genetic resistance to brown rust in sugarcane varieties. Thus, this study included 14 RB varieties, developed by RIDESA (Interuniversity Network for the Development of the Sugarcane Industry), which were among the 10 most cultivated varieties in the central-south region of Brazil in the period of 1974-2015. To evaluate the disease in the field an experiment was conducted in randomized blocks with four replicates. The severity of brown rust was quantified according to a diagrammatic scale ranging from 1 (most resistant) to 9 (most susceptible), and the obtained data were analyzed by using a generalized linear mixed model (GLMM). Concomitantly, total DNA was extracted from the 14 varieties, followed by amplification of the molecular markers, which were classified into haplotypes. Out of the total varieties, 12 had no symptoms of the disease and showed $99.35 \%$ probability of being resistant according to analysis via GLMM; among them, $91.66 \%$ were haplotype 1 , i.e., had the presence of both markers associated with $B r u 1$ gene. Therefore, we can conclude that the molecular markers R12H16 and 9O20-F4-RsaI were highly efficient in predicting resistant phenotypes and that $B r u 1$ gene is probably the main source of sugarcane resistance to brown rust in commercial fields in Brazil.

Keywords: Saccharum spp., breeding, Puccinia melanocephala, Bru1, disease resistance.

A cana-de-açúcar (Saccharum spp.) está entre as mais importantes espécies cultivadas, principalmente para produção de açúcar e bioetanol (1). O Brasil é atualmente o país com a maior produção de cana-deaçúcar com mais de nove milhões de hectares cultivados e produtividade estimada em $76.909 \mathrm{~kg} \mathrm{ha}^{-1}$ na safra 2015/16 $(1,2)$.

A cana-de-açúcar é uma gramínea semi-perene com propagação vegetativa, sendo que os programas de melhoramento genético têm concentrado esforços para o desenvolvimento e lançamento de novas variedades com rendimentos que atendam às demandas atuais e as perspectivas do setor sucroenergético $(3,4)$. No entanto, o processo de melhoramento é longo e extremamente trabalhoso, pois envolve a obtenção de milhares de indivíduos de progênies F1 todo ano, seguido por 12 a 15 anos de seleção e experimentação a campo $(5,6)$.

Além disso, a complexidade genética tem dificultado o melhoramento desta cultura. As variedades comerciais de canade-açúcar foram resultados de cruzamentos interespecíficos entre Saccharum officinarum L. $(2 \mathrm{n}=80)$ e $S$. spontaneum $(2 \mathrm{n}=40-120)$, seguido por vários retrocruzamentos com $S$. officinarum $(7,8)$. A 
complexidade do genoma da cana-de-açúcar é devido ao seu elevado número de cromossomos, variando de 100 a $130(8,9)$; ao tamanho do genoma, com aproximadamente $10 \mathrm{~Gb}(10,11,12)$; e à ocorrência de aneuploidia, com um número variável de cromossomos em cada grupo de homeologia (13). Desta forma, a obtenção de variedades com alta performance agrícola torna-se um grande desafio $(14,15,16,17)$.

Entre as doenças que causam perdas relevantes na cana-de-açúcar, a ferrugem marrom, causada pelo fungo Puccinia melanocephala $\mathrm{H}$. \& P. Sydow., está presente em quase todas as áreas de cultivo $(18,19,20)$. Em variedades suscetíveis, o patógeno prejudica a taxa fotossintética e vias correlatas, ocasionando reduções na altura e diâmetro dos colmos e na quantidade de perfilhos, comprometendo a produção final de biomassa (19, 21, 22, 23). No México, nos anos de 1981 e 1982, foram registrados prejuízos de até $50 \%$ na produção de cana-de-açúcar devido à doença (22). No Brasil, em 1992, estima-se que o prejuízo na produção chegou a $8,74 \%$ e as perdas a US\$107 milhões devido ao cultivo predominante de genótipos que não apresentavam níveis satisfatórios de resistência (24).

O método mais eficaz para controlar a ferrugem marrom é o uso de variedades resistentes $(14,25,26,27,28,29)$. A base da herança genética de resistência a essa doença tem sido amplamente estudada e alguns autores defendem que a resistência é controlada por um ou poucos genes $(18,25,26,27,28,29,30,31,32,33)$. Um gene de resistência, denominado $B r u 1$, foi o primeiro caráter mendeliano descrito para o complexo genoma da cana-de-açúcar $(18,26,30,32)$.

Costet et al. (25) mostraram que nas variedades modernas de canade-açúcar a resistência à ferrugem marrom depende essencialmente do gene Bru1. Estudos genômicos têm mostrado que Bru1 está incluído numa inserção de tamanho desconhecido $(31,34)$. Esta inserção induz redução de recombinação, resultando em forte desequilíbrio de ligação (LD) na região Bru1 e um completo LD entre dois marcadores moleculares, R12H16 e 9O20-F4. Estes representam valiosos marcadores diagnósticos para a presença de Brul, sendo possível, através deles, prever o comportamento resistente em genótipos de canade-açúcar $(25,26,28,29)$. Além disso, a ausência destes marcadores em uma variedade resistente indicaria uma possível fonte alternativa de resistência $(25,26,27,28,29)$. O objetivo deste estudo foi avaliar a eficiência dos marcadores moleculares R12H16 e 9O20-F4-RsaI na predição de resistência genética de variedades de cana-de-açúcar à ferrugem marrom.

\section{MATERIAL E MÉTODOS}

\section{Material vegetal e avaliação da severidade da ferrugem marrom}

Foram utilizadas 14 variedades RB de cana-de-açúcar, desenvolvidas pela Rede Interuniversitária para o Desenvolvimento do Setor Sucroenergético (RIDESA). Essas variedades figuraram entre as 10 mais cultivadas na região Centro-Sul do Brasil considerando censos varietais do período de 1974 a $2015(3,35)$. Os genótipos foram avaliados em dois ciclos de cultivo (cana planta e cana soca), em condição natural de infecção, no Centro de Ciências Agrárias (22²1'25' S, 47²3'3" W) da Universidade Federal de São Carlos (UFSCar). As avaliações foram realizadas em fevereiro de 2014 em cana-planta e em fevereiro de 2015 em cana-soca, períodos favoráveis para ocorrência da ferrugem marrom, considerando condições de temperatura $\left(17^{\circ} \mathrm{C}\right.$ a $\left.30^{\circ} \mathrm{C}\right)$ e umidade (36). As avaliações foram conduzidas em plantas com idade de cinco meses, quando elas se mostram mais suscetíveis à ferrugem marrom (37). O delineamento experimental foi em blocos casualizados com quatro repetições, sendo cada parcela experimental composta por duas linhas de $3 \mathrm{~m}$ de comprimento e espaçamento de 1,40 $\mathrm{m}$ entre as linhas. A severidade da ferrugem marrom foi verificada visualmente em folhas +3 de dez plantas de cada parcela, atribuindo-se notas de 1 ( $0 \%$ de área foliar com sintomas) a 9 (mais de $50 \%$ de área foliar com sintomas), considerando a escala diagramática de Amorim et al. (38).

\section{Análises moleculares}

Os primórdios foliares de cada variedade foram utilizados para a extração do DNA genômico total seguindo o método CTAB descrito por Al-Janabi et al. (39). As amostras foram quantificadas em gel de agarose $1 \%$ através de comparação com concentrações conhecidas do DNA do fago lambda $(\lambda)$ e armazenadas em freezer a $-20^{\circ} \mathrm{C}$. Os dois marcadores moleculares de diagnóstico, R12H16 e 9O20-F4-RsaI, fortemente associados ao gene Bru1 (25), foram utilizados para avaliar a presença do gene. As reações de PCR foram realizadas seguindo o protocolo: $20 \mu \mathrm{L}$ de volume final contendo $50 \mathrm{ng}$ de DNA, $0.4 \mu \mathrm{M}$ de cada primer, $0.4 \mathrm{mM}$ de cada dNTP, $2.5 \mathrm{mM} \mathrm{MgCl}, 0.5$ unidade de Taq DNA Polymerase (Invitrogen) com 1 X PCR buffer fornecido junto com a enzima (40).

As reações foram realizadas no termociclador Mastercycler gradient $\left(\right.$ Eppendorf $^{\circledR}$ ) seguindo o protocolo: 4 min de desnaturação inicial a $94^{\circ} \mathrm{C}$, seguido por 35 ciclos de $94^{\circ} \mathrm{C}$ por $30 \mathrm{~s}, 55.5^{\circ} \mathrm{C}$ por $45 \mathrm{~s}, 72^{\circ} \mathrm{C}$ por $72 \mathrm{~s} \mathrm{e}$ extensão final por $8 \mathrm{~min}$ a $72^{\circ} \mathrm{C}$. O marcador R12H16 foi amplificado com o par de primers: Fw: CTACGATGAAACTACACCCTTGTC/ Rv: CTTATGTTAGCGTGACCTA, que corresponde a um fragmento específico de aproximadamente $570 \mathrm{pb}$, cuja presença está associada ao gene Bru1. Para observar o resultado diagnóstico utilizando o par de primers 9O20-F4 (Fw: TACATAATTTTAGTGGCACTCAGC/ Rv:ACCATAATTCAATTCTGCAGGTAC) é necessária digestão do produto de amplificação com enzima de restrição RsaI. Volume de $15 \mu \mathrm{L}$ do produto de PCR 9O20-F4 foi digerido para visualizar a presença de uma banda específica de aproximadamente $270 \mathrm{pb}$ associada ao gene Bru1. Os produtos de PCR do marcador R12H16 e os fragmentos restringidos do marcador $9 \mathrm{O} 20-\mathrm{F} 4-\mathrm{RsaI}$ foram visualizados após eletroforese em gel de agarose $1,5 \%$ e 3\%, respectivamente, por coloração com brometo de etídio. O acesso R570 foi utilizado como controle positivo.

Variedades que apresentaram os fragmentos dos dois marcadores foram classificados como haplótipo 1, e aquelas variedades que não apresentaram nenhum dos dois fragmentos foram classificados como haplótipo 4. Variedades que continham somente o fragmento amplificado pelo marcador R12H16 foram classificados como haplótipo 2, e aquelas variedades que apresentaram apenas o fragmento amplificado pelo marcador 9O20-F4-RsaI foram classificados como haplótipo 3. Através de probabilidade condicional para o haplótipo 1, utilizando um limiar de severidade à ferrugem marrom igual a 1.0, foi verificada a eficiência dos marcadores em predizer o fenótipo resistente. A análise dos resultados foi feita comparando-se as respostas dos haplótipos dos marcadores com a avaliação a campo usando modelo misto linear generalizado, conforme proposto por Balsalobre et al. (14).

\section{RESULTADOS E DISCUSSÃO}

Os resultados da avaliação de severidade à ferrugem marrom, da probabilidade de resistência obtida através de modelo misto linear generalizado e dos haplótipos dos marcadores associados com a resistência à doença para as 14 variedades estudadas estão sumarizados na Tabela 1. Com exceção para RB806043 e RB835486, todas as 
variedades foram resistentes à ferrugem marrom nas avaliações a campo. Do total de variedades resistentes, $91,66 \%$ foram haplótipo 1 para os marcadores moleculares associados com o gene de resistência à ferrugem marrom.

As variedades foram classificadas em dois grupos: a) até $10 \%$ de probabilidade de apresentar a doença; e b) entre 90\% e 100\% de probabilidade de apresentar doença (Figura 1). Todas as variedades resistentes foram alocadas no primeiro grupo, ou seja, apresentaram no mínimo $90 \%$ de probabilidade de serem resistentes. De fato, todas as variedades que não apresentaram sintomas da doença no campo mostraram probabilidade de $99,35 \%$ de serem resistentes.

A grande utilidade dos marcadores moleculares associados ao gene
Bru 1 foi demonstrado no conjunto de 14 variedades, visto que $91,66 \%$ das variedades que possuíam os dois marcadores foram resistentes à ferrugem marrom nas condições experimentais avaliadas. Em adição, as variedades suscetíveis RB806043 e RB835486 foram haplótipo 2 e haplótipo 4, respectivamente.

Programas de melhoramento genético da cana-de-açúcar podem se beneficiar da alta eficiência dos marcadores associados ao gene Bru1 na predição de fenótipos resistentes à ferrugem marrom. Em trabalho realizado por Costet et al. (25), 85,56\% dos acessos de bancos de germoplasma de cana-de-açúcar classificados como resistentes possuíam o haplótipo 1. Glynn et al. (26) mostraram que o gene Bru1 é a principal fonte de resistência à ferrugem marrom do programa

Tabela 1. Variedades de cana-de-açúcar, época de maturação, avaliação a campo da severidade à ferrugem marrom, probabilidade de resistência calculada através de modelo misto linear generalizado e haplótipos dos marcadores R12H16 e 9O20-F4-RsaI associados ao gene Bru1.

\begin{tabular}{|c|c|c|c|c|c|}
\hline Variedades & Maturação & Avaliação 2014 & Avaliação 2015 & Probabilidade de ser resistente (\%) & Haplótipo \\
\hline RB765418 & Média & $\mathrm{R}\left(1.0^{*}\right)$ & $\mathrm{R}\left(1.0^{*}\right)$ & 99.35 & 1 \\
\hline RB785148 & Tardia & $\mathrm{R}\left(1.0^{*}\right)$ & $\mathrm{R}\left(1.0^{*}\right)$ & 99.35 & 1 \\
\hline RB806043 & Média & $\mathrm{S}(1.22 *)$ & $\mathrm{S}(1.07 *)$ & 0.07 & 2 \\
\hline RB835054 & Precoce & $\mathrm{R}\left(1.0^{*}\right)$ & $\mathrm{R}\left(1.0^{*}\right)$ & 99.35 & 1 \\
\hline RB835486 & Média & $\mathrm{S}\left(2.6^{*}\right)$ & $\mathrm{S}(3.82 *)$ & 0.07 & 4 \\
\hline RB855156 & Precoce & $\mathrm{R}\left(1.0^{*}\right)$ & $\mathrm{R}\left(1.0^{*}\right)$ & 99.35 & 1 \\
\hline RB855453 & Média & $\mathrm{R}\left(1.0^{*}\right)$ & $\mathrm{R}\left(1.0^{*}\right)$ & 99.35 & 1 \\
\hline RB855536 & Média & $\mathrm{R}\left(1.0^{*}\right)$ & $\mathrm{R}\left(1.0^{*}\right)$ & 99.35 & 1 \\
\hline RB867515 & Média & $\mathrm{R}\left(1.0^{*}\right)$ & $\mathrm{R}\left(1.0^{*}\right)$ & 99.35 & 1 \\
\hline
\end{tabular}

* Nota média de severidade à ferrugem marrom considerando quatro repetições. R: resistente (nota 1); S: suscetível $(1<$ notas $\leq 9)$.

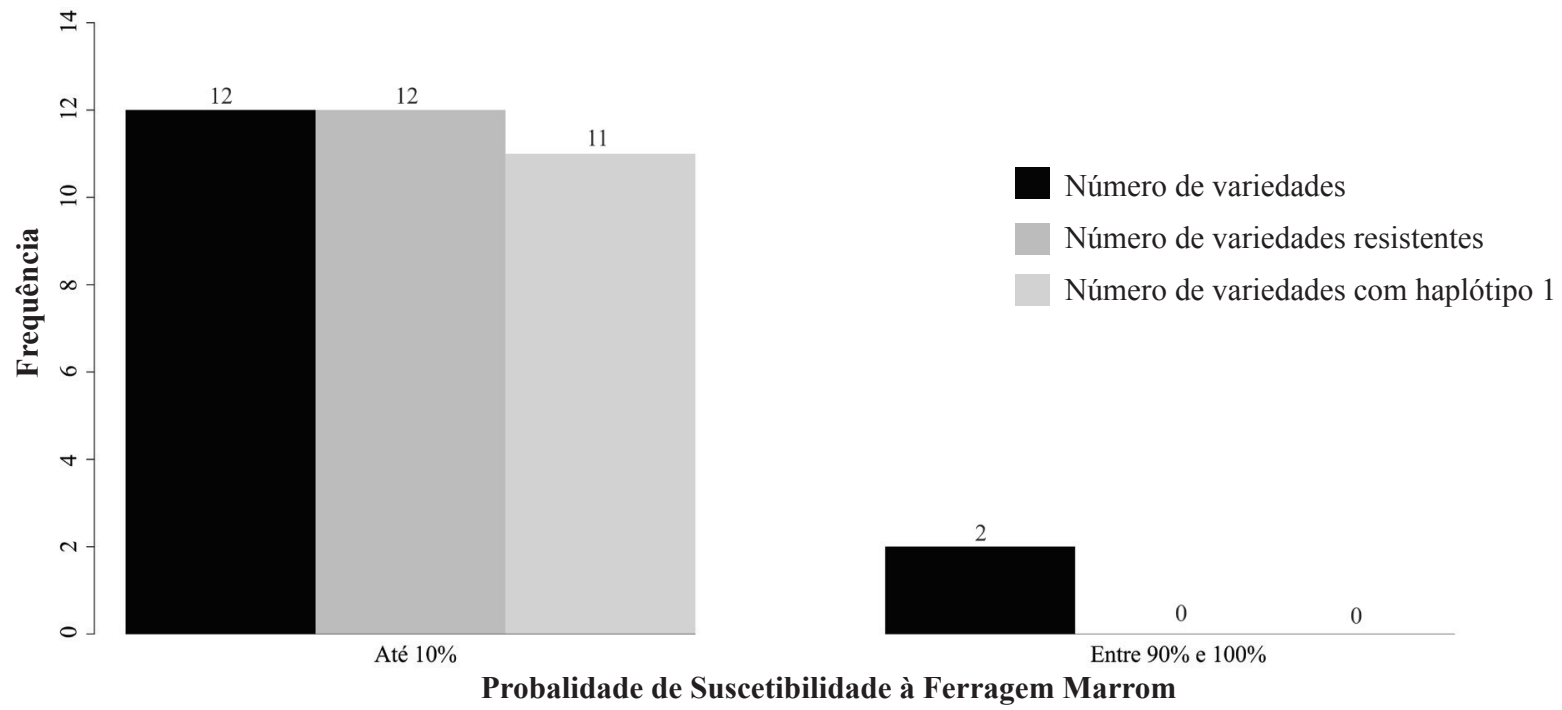

Figura 1. Frequência das 14 variedades de cana-de-açúcar em duas classes de probabilidade de suscetibilidade à ferrugem marrom: até $10 \%$ e entre $90 \%$ e $100 \%$. Os valores de probabilidade foram obtidos através de modelo misto linear generalizado, considerando quatro repetições de cada variedade e avaliações em dois anos agrícolas, 2014 e 2015. 
de melhoramento genético de Canal Point, na Flórida (EUA). Estes resultados corroboram com os obtidos neste estudo. De maneira geral, os programas de melhoramento poderiam utilizar os marcadores moleculares associados ao gene de resistência à ferrugem marrom, Bru1, para direcionar cruzamentos e para selecionar clones com a presença dos marcadores, dado pelo haplótipo 1, ou descartar em etapas futuras do processo de melhoramento clones com a ausência dos marcadores, dado pelo haplótipo 4. Desde de 2009 a informação dos marcadores tem sido utilizada pelo programa de melhoramento de Canal Point para direcionar estratégias de melhoramento para resistência à ferrugem marrom $(26,41)$.

Possivelmente em decorrência de fatores como clima e variabilidade genética do patógeno, os programas de melhoramento genético da cana-de-açúcar da Louisiana (EUA) e de Tucumán (Argentina) possuem predominância de fonte alternativa de resistência à ferrugem marrom, visto que em ambos os programas o gene Bru 1 tem baixa frequência nos acessos resistentes $(26,28$, 29). Na Argentina, por exemplo, as condições climáticas favorecem a ocorrência de alto nível de variabilidade do patógeno $(42,43)$ e, consequentemente, aumenta a possibilidade de ocorrência de genótipos virulentos do patógeno que podem não ser controlados por Bru1. No entanto, Asnaghi et al. (44), utilizando isolados de P. melanocephala de diferentes locais (Brasil, Colômbia, Estados Unidos, Guadalupe, Ilhas Reunião e Zimbábue) na variedade R570 demonstraram que o gene $B r u 1$ foi responsável pela resistência a todos os isolados.

Outro ponto importante a ser destacado é a classificação das variedades em resistentes e suscetíveis, visto que variedades com a presença de poucas pústulas (nota 2 na escala diagramática) foram consideradas como suscetíveis neste estudo e também por Costet et al. (25) e Glynn et al. (26), mas como resistentes por Racedo et al. (28) e Racedo et al. (29). Nestes dois últimos trabalhos ocorre, portanto, diminuição da associação entre haplótipo 1 e variedades sem os sintomas da doença, impactando negativamente sobre a taxa de eficiência dos marcadores moleculares associados ao gene Brul.

Durante as avaliações a campo, as variedades RB835089 e RB806043 mostraram reação de resistência e suscetibilidade, respectivamente, à ferrugem marrom. Em adição, através da avaliação molecular com os marcadores diagnósticos de Bru1, as variedades RB835089 e RB806043 foram haplótipo 3 e haplótipo 2, respectivamente. Estes resultados podem indicar que uma possível fonte alternativa confere resistência à variedade RB835089 ou, ainda, que esta variedade pode não ter sido suficientemente exposta ao fungo causador da doença nos dois anos de avaliação e deve ser experimentada em outros locais. Além disso, também é possível a ocorrência de um evento raro de recombinação entre os marcadores moleculares associados ao gene Bru1 tanto para RB835089 como para RB806043. Pesquisas adicionais para determinação de fontes alternativas de resistência à ferrugem marrom devem ser conduzidas de forma controlada, bem como análises moleculares aprofundadas, visto que as duas variedades tiveram detectados pelo menos um dos dois marcadores associados ao gene Bru1.

O gene $B r u 1$ pode ser a principal fonte de resistência de variedades de cana-de-açúcar à ferrugem marrom nas condições brasileiras de cultivo.

Os marcadores moleculares R12H16 e 9O20-F4-RsaI são eficientes em detectar Bru1 e podem ser usados com sucesso em seleção assistida nos programas brasileiros de melhoramento genético de cana-de-açúcar.

\section{AGRADECIMENTOS}

Este estudo foi apoiado pelo INCT-Bioetanol (Instituto Nacional de Ciência e Tecnologia do Bioetanol), CAPES (Coordenação de Aperfeiçoamento de Pessoal de Nível Superior) e FAPESP (Fundação de Amparo a Pesquisa de São Paulo).

\section{CONFLITOS DE INTERESSE}

Os autores declaram que não possuem conflitos de interesse.

\section{REFERÊNCIAS}

1. FAOSTAT. Food and Agriculture Organization of the United Nations. Disponível em: <http://faostat.fao.org/site/567/DesktopDefault.aspx?PageID $=567 \#$ anco $>$. Acesso em: 10 nov. 2015.

2. CONAB - COMPANHIA NACIONAL DE ABASTECIMENTO. Cana-ded -açúcar, Safra, 2015/2016. Quarto levantamento, Maio de 2016. Disponível em: $<$ http://www.conab.gov.br/conteudos.php?a=1253\&t=2>. Acesso em: 10 jun. 2016

3. Dal-Bianco, M; Carneiro, M.S.; Hotta, C.T.; Chapola, R.G.; Hoffmann, H.P.; Garcia, A.A.F.; Souza, G.M. Sugarcane improvement: how far can we go? Current Opinion Biotechnology, [S.I], v.23, p.265-270, 2012.

4. Waclawovsky, A.J.; Sato, P.M.; Lembke, C.G.; Moore, P.H.; Souza, G.M. Sugarcane for bioenergy production: An assessment of yield and regulation of sucrose content. Plant Biotechnology Journal, [S.I.], v.8, p.263-276, 2010.

5. Gouy, M.; Rousselle, Y.; Bastianelli, D.; Lecomte, P.; Bonnal, L.; Roques, D.; Efile, J.-C.; Rocher, S.; Daugrois, J.; Toubi, L., Nabeneza, S.; Hervouet, H.; Telismart, H.; Denis, M.; Thong-Chane, A.; Glaszmann, J.C.; Hoarau, J.-Y.; Nibouche, S.; Costet, L. Experimental assessment of the accuracy of genomic selection in sugarcane. Theoretical and Applied Genetics, [S.I.], v.126, p.2575-2586, 2013.

6. Matsuoka, S.; Ferro, J.; Arruda, P. The Brazilian experience of sugarcane ethanol industry. In Vitro Cellular \& Developmental Biology - Plant, [S.I.], v.45, p.372-381, 2009.

7. Ha, S.; Moore, P.H.; Heinz, D.; kato, S.; Ohmido, N.; Fukui, K. Quantitative chromosome map of the polyploid Saccharum spontaneum by multicolor fluorescence in situ hybridization and imaging methods. Plant Molecular Biology, [S.I.], v.39, p.1165-1173, 1999.

8. Irvine, J.E. Saccharum species as horticultural classes. Theoretical and Applied Genetics, [S.I.], v.98, p.186-194, 1999.

9. D’Hont, A.; Ison, D.; Alix, K.; Roux, C.; Glaszman, C. Determination of basic chromosome numbers in the genus Saccharum by physical mapping of ribosomal RNA genes. Genome, [S.I.], v.41, p.221-225, 1998.

10. D'Hont, A. Unravelling the genome structure of polyploids using FISH and GISH; examples in sugarcane and banana. Cytogenetic and Genome Research, [S.I.], v.109, p.27-33, 2005.

11. D'Hont, A.; Glaszmann, J.C. Sugarcane genome analysis with molecular markers, a first decade research. Proceedings of the International Society of Sugarcane Technologists, Montpllier, v.24, p.556-559, 2001.

12. Piperidis, G.; Piperidis, N.; D’Hont, A. Molecular cytogenetic investigation of chromosome composition and transmission in sugarcane. Molecular Genetics and Genomics, [S.I.], v.284, p.65-73, 2010.

13. Grivet, L.; Arruda, P. Sugarcane genomics: depicting the complex genome of an important tropical crop. Current Opinion in Plant Biology, [S.I.], v.5, p.122-127, 2002.

14. Balsalobre, T.W.A.; Mancini, M.C.; Pereira, G.S.; Anoni, C.O.; Barreto, F.Z.; Hoffmann, P.H.; Souza, A.P.; Garcia, A.A.F.; Carneiro, M.S. Mixed Modeling of Yield Components and Brown Rust Resistance in Sugarcane Families. Agronomy Journal, [S.I.], v.108, p.1-14, 2016.

15. Gouy, M.; Luquet, D.; Rouan, L.; Martiné, J.-F.; Thong-Chane, A.; Costet, L.; Nibouche, S.; Gozé, E. Site and Saccharum spontaneum introgression level drive sugarcane yield component traits and their impact on sucrose yield in contrasted radiation and thermal conditions in la Réunion. Field Crops Research, [S.I.], v.171, p.99-108, 2015.

16. Welham, S.J.; Gogel, B.J.; Smith, A.B.; Thompson, R.; Cullis, B.R. A comparison of analysis methods for late-stage variety evaluation trials. Australian \& New Zealand Journal of Statistics, [S.I.], v.52, p.125-149, 2010. 
17. Zangh, F.-J.; Zhang, K.-K.; Du, C.-Z.; Li, J.; Xing, Y.-X.; Yang, L.-T.; Li, Y.-R. Effect of Drought Stress on Anatomical Structure and Chloroplast Ultrastructure in Leaves of Sugarcane. Sugar Tech, [S.I], v.17, n. 1, p.4148, 2015.

18. Asnaghi, C.; Roques, D.; Ruffel, S.; Kaye, C.; Hoarau, J.-Y.; Télismart, H.; Girard, J.C.; Raboin, L.M.; Risterucci, A.M.; Grivet, L.; D’Hont, A. Targeted mapping of a sugarcane rust resistance gene (Bru1) using bulked segregant analysis and AFLP markers. Theoretical and Applied Genetics, [S.I.], v.108, n.4, p.759-64, fev. 2004.

19. Hoy, J.W.; Hollier, C.A. Effect of brown rust on yield of sugarcane in Louisiana. Plant Disease, [S.I.], v.93, p.1171-1174, 2009.

20. Ryan, C.C.; Egan, B.T. Rust. In: C. Ricaud and B.T. Egan, (Ed.). Diseases of sugarcane: Major diseases. Amsterdam: Elsevier Science, 1989. p. $189-210$.

21. McFarlane, K.; McFarlane S.A.; Moodley, D.; Rutherford, R.S. Fungicide trials to determine the effect of brown rust on the yield of sugarcane variety. Proceedings of the South African Sugar Technologists' Association, Mount Edgecombe, v.29, p.297-300, 2006.

22. Purdy, L.H.; Liu, L.J.; Dean, J.L. Sugarcane rust, a newly important disease. Plant Disease, [S.I.], v.67, p.1292-1296, 1983.

23. Raid, R.N.; Comstock, J.C. Common rust. In: P. ROTT et al. (Ed.). A guide to sugarcane diseases. Montpellier: CIRAD and ISSCT, 2000. p.85-89.

24. Moura, G.L; Gheller, A.C.A.; Matsuoka, S.; Giglioti E.A. The impact of rust (P. melanocephala) on Sugarcane Production in the State of São Paulo. 1999, Curitiba. Anais. Fitopatologia Brasileira, Curitiba-SP, v. 24, supl., p.279-279. 1999. (Resumo).

25. Costet, L.; Le Cunff, L.; Royaert, S.; Raboin, L.M.; Hervouet, C.; Toubi, L.; Telismart, H.; Garsmeur, O.; Rousselle, Y.; Pauquet, J.; Nibouche, S.; Glaszmann, J.C.; Hoarau, J.Y.; D'Hont, A. Haplotype structure around Bru1 reveals a narrow genetic basis for brown rust resistance in modern sugarcane cultivars. Theoretical and Applied Genetics, [S.I.], v.125, n.5, p.825-36, set. 2012

26. Glynn, N.C.; Laborde, C.; Davidson R.W.; Irey, M.S.; Glaz, B.; D $\square$ Hont, A.; Comstock, J.C. Utilization of a major brown rust resistance gene in sugarcane breeding. Molecular Breeding, [S.I.], v.31, n.2, p.323-331, 2013.

27. Parco, A.S.; Avellaneda, M.C.; Hale, A.H.; Hoy, J.W.; Kimbeng, C.A.; Pontif, M.J.; Gravois, K.A.; Baisakh, N. Frequency and distribution of the brown rust resistance gene Bru1 and implications for the Louisiana sugarcane breeding programme. Plant Breeding, [S.I], 1-6. 2014.

28. Racedo, J.; Perera, M.F.; Bertani, R.; Funes, C.; González, V.; Cuenya, M.I.; D'Hont, A.; Welin B.; Castagnaro, A.P. Bru1 gene and potential alternative sources of resistance to sugarcane brown rust disease. Euphytica, [S.I], v.191, p.429-436, 2013

29. Racedo, J.; Perera, M.F.; Bertani, R.; Funes, C.; González, V.; Cuenya, M.I.; D'Hont, A.; Welin, B.; Castagnaro, A.P. Molecular diagnostic of both brown and orange sugarcane rust and evaluation of sugarcane brown rust resistance in Tucuman, Argentina, using molecular markers associated with $B r u 1$ a broad-range resistance allele. Sugar Tech, [S.I.], 18 (4), p. 414-419, 2016.

30. Daugrois, J. H.; Grivet, L.; Roques, D.; Hoarau, J.Y.; Lombard, H.; Glaszmann, J.C.; D'Hont, A. A putative major gene for rust resistance linked with a RFLP marker in sugarcane cultivar R570. Theoretical and Applied Genetics, [S.I], v.92, p.1059-1064, 1996.
31. Le Cunff, L.; Garsmeur, O.; Raboin, L.M.; Pauquet, J.; Telismart, H.; Selvi, A.; Grivet, L.; Philippe, R.; Begum, D.; Deu, M.; Costet, L.; Wing, R.; Glaszmann, J.C.; D'Hont, A. Diploid/polyploid syntenic shuttle mapping and haplotype-specific chromosome walking toward a rust resistance gene (Bru1) in highly polyploid sugarcane $(2 \mathrm{n} 12 \mathrm{x} 115)$. Genetics, [S.I.], v.180, p.649-660, 2008.

32. Raboin, L.M.; Oliveira, K.M.; Le Cunff, L.; Telismart, H.; Roques, D.; Butterfield, M.; Hoarau, J.Y.; D'Hont, A. Genetic mapping in sugarcane, a high polyploid, using bi-parental progeny: identification of a gene controlling stalk colour and a new rust resistance gene. Theoretical and Applied Genetics, [S.I], v.112, p.1382-1391, 2006.

33. Ramdoyal, R.; Sullivan S.; Chong, L.C.Y.L.S.; Badaloo, G.H.; Saumtally, S.; Domaingue, $R$. The genetics of rust resistance in sugarcane seedling populations. Theoretical and Applied Genetics, [S.I.], v.100, p.557-563, 2000.

34. Garsmeur, O.; Charron, C.; Bocs, S.; Jouffe, V.; Samain, S.; Couloux, A.; Droc, G.; Zini, C.; Glaszmann, J.C.; Van Sluys, M.A.; D’Hont, A. High homologous gene conservation despite extreme autopolyploid redundancy in sugarcane. New Phytologyst, [S.I.], v.189, p.629-642, 2011.

35. Chapola, R.G.; Júnior, A.R.F.; Cursi, D.E.; Hermann, P.H. Censo de variedades de cana-de-açúcar nos estados de São Paulo e Mato Grosso do Sul em 2015. STAB Açúcar, Álcool e Subprodutos, [S.I.], v. 34, n. 5, p. 37-39, 2016.

36. Barrera, W. Hoy, J.; Li, B. Effects of temperature and moisture variables on brown rust epidemics in sugarcane. Journal of Phytopathology, [S.I.], v. 161, p. $98-106,2013$

37. Dinardo-Miranda, L.L.; Silva, M.A.; Landell, M.G.A.; Campana, M.P. Reação de clones IAC de cana-de-açúcar à ferrugem. Summa Phytopathologica, [S.I.], v. 24, p.34-36, 1998.

38. Amorim, L.; Filho, B.A.; Sanguino, A.; Cardoso, C.O.N.; Moraes, V.A.; Fernandes, C.R. Metodologia de avaliação da ferrugem da cana-de-açúcar (Puccinia melanocephala). Boletim Técnico Coopersucar, [S.I.], v.39, p.13-16, 1987.

39. Al-Janabi, S.; Forget, L.; Dookun, A. An improved and rapid protocol for the isolation of polysaccharide-and polyphenol-free sugarcane DNA. Plant Molecular Biology Reporter, New York, v.17, n.3, p.281-281, 1999.

40. Oliveira, K.M.; Pinto, L.R.; Marconi, T.G.; Margarido, G.R.A.; Pastina, M.M.; Teixeira, L.H.M.; Figueira, A.V.; Ulian, E.C.; Garcia, A.A.F.; Souza, A.P. Functional integrated genetic linkage map based on EST-markers for a sugarcane (Saccharum spp.) commercial cross. Molecular Breeding, [S.I.], v.20, p.189-208, 2007.

41. Zhao, D.; Davidson, R.W.; Baltazar, M.; Comstock, J.C.; McCord, P.; Sood, S. Screening for Sugarcane Brown Rust in the First Clonal Stage of the Canal Point Sugarcane Breeding Program. Agronomy, [S.I.], v.5, p.341-362, 2015.

42. Pocovi, M.I.; Rech, G.E.; Collavino, N.G.; Caruso, G.B.; Ríos, R.; Mariotti, J.A. Molecular diversity of Puccinia melanocephala populations. Journal of Phytopathology, [S.I.], v.158, p.769-775, 2010.

43. Barrera, W.; Hoy, J.; Li, B. Temperature and Leaf Wetness Effects on Infection of Sugarcane by Puccinia melanocephala. Journal of Phytopathology, [S.I.], v.160, p.294-298, 2012.

44. Asnaghi, C.; D’Hont, A.; Glaszmann, J.C.; Rott, P. Resistance of sugarcane cultivar R 570 to Puccinia melanocephala isolates from different geographic locations. Plant disease, [S.I.], v.85, n.3, p.282-286, 2001. 